Bull. Chem. Soc. Ethiop. 2020, 34(2), 227-236.

ISSN 1011-3924

(c) 2020 Chemical Society of Ethiopia and The Authors

Printed in Ethiopia

DOI: https://dx.doi.org/10.4314/bcse.v34i2.2

\title{
DETECTION OF IRINOTECAN USING TITANIUM NANOPARTICLES MODIFIED
} ELECTRODE

\author{
Eman A. M. Al-Jawadi ${ }^{1 *}$ and Mohammed I. Majeed ${ }^{2}$ \\ ${ }^{1}$ Department of Biophysics, College of Science, University of Mosul, Mosul, Iraq \\ ${ }^{2}$ Department of Biology, College of Science, University of Mustansiriyah, Baghdad, Iraq
}

(Received October 24, 2019; Revised August 23, 2020; Accepted August 29, 2020)

\begin{abstract}
A tool has been developed in this study to estimate one of the Irinotecan (INR) cancer drugs used in the treatment of lung cancer by using square wave voltammetry (SWV) techniques, on surface of electrode graphite (GrE) and through of study the optimal condition that enhance the work of this electrode. The measurements are also enhanced by the electro-polymerization process of the neutral red pigment (NR) and using when presence of titanium nanoparticles $\left(\mathrm{TiO}_{2 \mathrm{NPs}}\right)$ to be greatly enhanced by measuring of LOD, LOQ and applied to human serum samples.
\end{abstract}

KEY WORDS: Irinotecan, Lung cancer, Square wave voltammetry, Titanium nanoparticles, Serum

\section{INTRODUCTION}

Irinotecan (INR) is (7-ethyl-10-[4-(1-piperidino)-1-piperidino]-carbonyloxycamp-tothecine) (Figure 1). It is a semi-synthetic derivative of cambotsin that have an alkaline character which occurs naturally. It is used as a chemotherapeutic agent in a treatment of cancer specially in colorectal [1,2]. INR It is one of the main drugs for anti-cancer chemotherapy [3].

The mechanism action of INR the inhibition of topoisomerase I, an enzyme essential to organize an important DNA processes, guaranty repair and transcription resulting DNA damage. Activity of topoisomerase I inhibits DNA transcription and replication, and ultimately leads to cell death $[4,7]$. In addition, the activity of INR is enhanced when photocatalytic activation [8].

INR determination for general method is (HPLC) [9], this method used was time consuming and expensive. Methods of electrochemistry open a new direction in pharmaceuticals estimation. Many research groups give drugs estimation in different electrochemical methods for in biological fluids and pharmaceutical formulations [10-21]. Electrochemical estimation has been used for electroactive species determination in body fluids and pharmaceuticals because low cost and simplicity. Only one study investigated the electrochemical behavior of oxidation, reduction and interference with dsDNA (double stranded RNA) with INR using the hanging drop mercury electrode [22]. The production of measurements using PNR as an electrolysis polymer is very important in improving the functioning of the biosensors. Various supports have been designed to improve NR polymerization conditions, such as indium tin oxide (ITO) platinum electrodes and glass carbon electrodes. In addition to the electropolymerization process there are other methods like immobilization techniques. It was explored to produce a strong medium by promoting electronic transport such as covalent direct bonding or direct chemical absorption of a polymer carrying functional groups of oxidation reduction cells mixed with carbon paste [23]. The aim of this study is to develop biosensors to measure the smallest possible amounts of biological models for patients with cancer who use a treatment.

*Corresponding author. E-mail: e_abd2012@yahoo.com

This work is licensed under the Creative Commons Attribution 4.0 International License 


\section{EXPERIMENTAL}

\section{Apparatus}

Measurements were made using the study's SWV technique and to estimate INR concentrations in human serum samples using an electrochemical analyzer stand 797VA (Metrohm AG, CH9101 Herisav). A traditional three-electrode device comprised of three electrode cells, including a reference electrode (RE), an auxiliary electrode a Pt electrode, a $(3.0 \mathrm{~mm})$ bare graphite electrode (Homemade, Germany) and a modified electrode as a working electrode were performed. The graphite rods were designed using epoxy glue (UHU plus endfest 300) to seal industrial graphite rods (diameter $3.05 \mathrm{~mm}$; SGL Carbon, Bonn, Germany) in glass tubes (outer diameter $5 \mathrm{~mm})$. All tests were performed under room temperature $\left(25.0 \pm 0.5{ }^{\circ} \mathrm{C}\right) . \mathrm{pH}$ measurements were performed using a digital $\mathrm{pH}$ meter (HANNA, Portugal). Ultrasonic cleaner (model CD-4820, China), centrifuge (HERMLE-Z200A, Germany) used to separate the serum, scanning electron microscope (SEM) (model: VEGA Tescan $3 \mathrm{SB}$, Czech).

\section{Reagents and chemicals}

Koçak Farma Inc. (Istanbul, Turkey) provided the dosage type for the medication and INR. Nanol $\mathrm{TiO}_{2}$ particles (Anhui Elite Industrial Co., Ltd. (China) was used. Phosphate buffers was used as electrolyte supports. The remaining materials used in the study were supplied by Fluka and BDH and used without further washing. To avoid oxidation, the solutions were prepared and used for 24 hours, and kept away from light.

\section{Collection of serum samples}

The Nuclear Medicine and Oncology Hospital in Mosul City has obtained samples of patients with lung cancer who were taking chemotherapy doses containing INR. The blood serum was isolated after the samples were obtained, and the measurements were re-examined separately.

\section{Cleaning and polishing electrode}

The polishing and cleaning of electrodes is performed using emery paper and alumina oxide with various minutes $(3,1.0,0.3,0.05 \mu \mathrm{M})$ and regularly well washing with double distilled water. We should be careful to wash by distilled water after using each amount of alumina volumes and sonicate in distilled water (DSW) for $15 \mathrm{~min}$ to achieve a mirror-like surface and dry in the air before being used for modulation [24].

\section{Electropolymerization of $\mathrm{NR}$ on $\mathrm{TiO}_{2 \mathrm{NPS}} / \mathrm{GrE}$}

NR electrochemical polymerization was performed on the surface of the Gr electrode using the technique of cyclic voltammetry $(\mathrm{CV})$ within the range of (0.2-1.2 V) versus reference electrode $(\mathrm{Ag} / \mathrm{AgCl})$ before being used with acetone and distilled water (DSW) sonicated for $15 \mathrm{~min}$, respectively [25]. After refining the geo-graphite electrode with various sizes of alumina oxide and then applying a suitable amount of $\mathrm{TiO}_{2 \mathrm{NPs}}$ on the surface of the electrode by means of a pre-suspended suspension solution and drying it at the room temperature (referred to as: $\left.\mathrm{TiO}_{2} \mathrm{NPs} / \mathrm{GrE}\right)$. At $\mathrm{pH}(\mathrm{pH}=6.0)$ of the phosphate solution buffer containing $0.05 \mathrm{mM}$ of NR and $0.2 \mathrm{M}\left(\mathrm{KNO}_{3}\right)$, the NR oxidation-reduction current is increased by increasing the number of cycles until it is stabilized at 11 cycles at a scan rate of $50 \mathrm{mV} / \mathrm{s}$ (Scheme 1). After the electrochemical polymerization process the electrode was treated by distilled water (DSW), then left to dry in the air. 


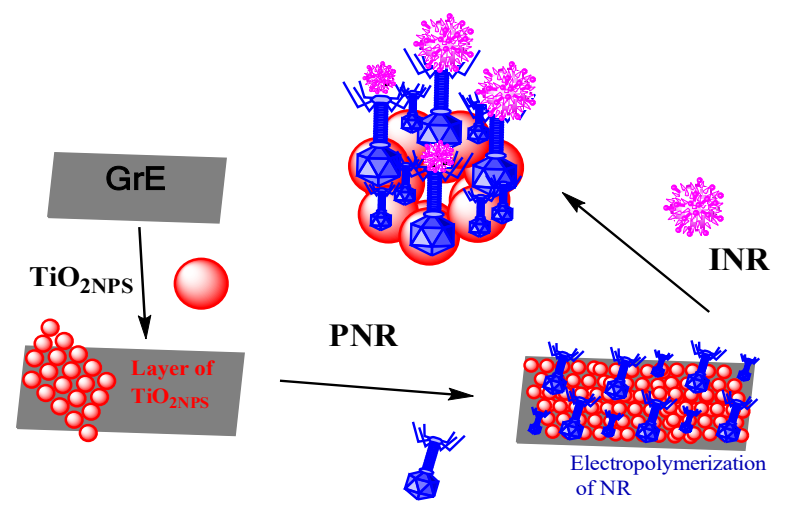

Scheme 1. Electropolymerization of $\mathrm{NR}$ on $\mathrm{TiO}_{2 \mathrm{NPs}} / \mathrm{GrE}$.

RESULTS AND DISCUSSION

INR voltammetric study

INR is considered to be an effective electrochemical pharmaceutical compound, a study of electrochemical behavior on various electrodes, such as graphite electrodes $(\mathrm{GrE})$, as well as modified electrodes in the various modulations which will be gradually mentioned. The voltage approximation for INR using the SWV techniques was tested at $0.05 \mu \mathrm{M}$. Measurements were carried out at $\mathrm{pH} 4.0-10.0$ in the phosphate solution buffer. $\mathrm{Ag} / \mathrm{AgCl}$ has been swept off the promise. Figure 1 displays the square-wave voltammogram obtained on a bare graphite electrode for $0.05 \mu \mathrm{M}$ of INR. This is the related current of the electrochemical operation of the product from the redox mechanism of the compound which gave this current for this potential value.

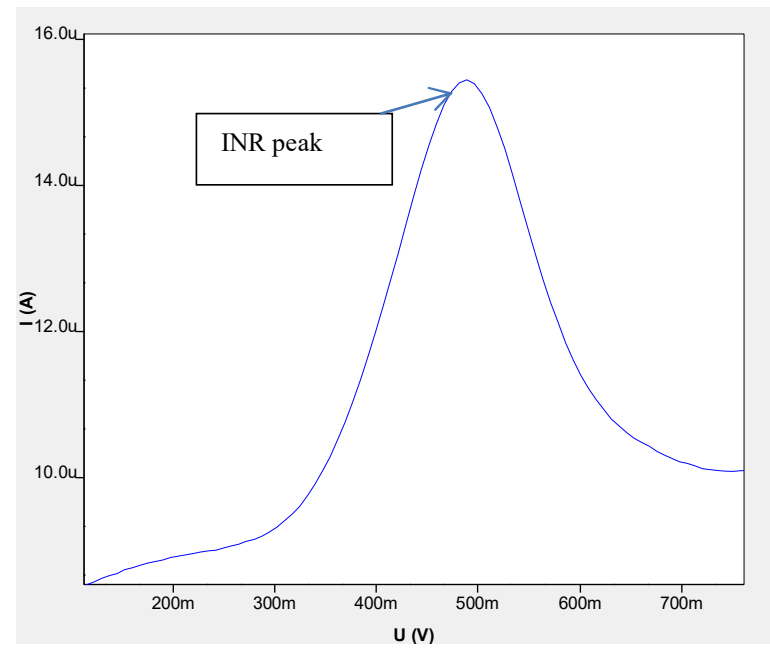

Figure 1. SWV of INR in $0.2 \mathrm{M}$ PBS at $\mathrm{pH}$ 7.0.

Bull. Chem. Soc. Ethiop. 2020, 34(2) 
Optimal conditions for INR measurement

A series of experiments were performed using SWV technique by adding the daily INR solution to the phosphate solution buffer at $0.05 \mu \mathrm{M}$ concentration at $\mathrm{pH}$ 7.0. By continuously adjusting the device's initial conditions and obtaining the best results, the highest values of the measured current and the best form of the resulting voltammogram were provided with the survival of the static peak potential as indicated in Table 1 .

Table 1. Optimum conditions for detection of $0.05 \mu \mathrm{M}$ INR in PBS at $\mathrm{pH} 7.0$ to give optimum highest current.

\begin{tabular}{|l|l|}
\hline Optimum parameters & Assess \\
\hline Start potential & $0.0 \mathrm{~V}$ \\
\hline End potential & $0.8 \mathrm{~V}$ \\
\hline Voltage step & $0.0075 \mathrm{~V}$ \\
\hline Equilibration time & $30 \mathrm{~s}$ \\
\hline Frequency & $50 \mathrm{~Hz}$ \\
\hline Deposition potential & $-0.9 \mathrm{~V}$ \\
\hline Deposition time & $35 \mathrm{~s}$ \\
\hline Amplitude & $0.035 \mathrm{~V}$ \\
\hline
\end{tabular}

Effect of $p H$

INR's SW voltammetry was measured using the graphite electrode (GrE) at different potential. The voltammetry estimation was analyzed at $\mathrm{pH}=4.0-10.0$ in $0.2 \mathrm{M}$ PBS at concentration 0.05 $\mu \mathrm{M}$ INR using SWV as shown in Figure 2A using the optimum conditions described in Table 1.
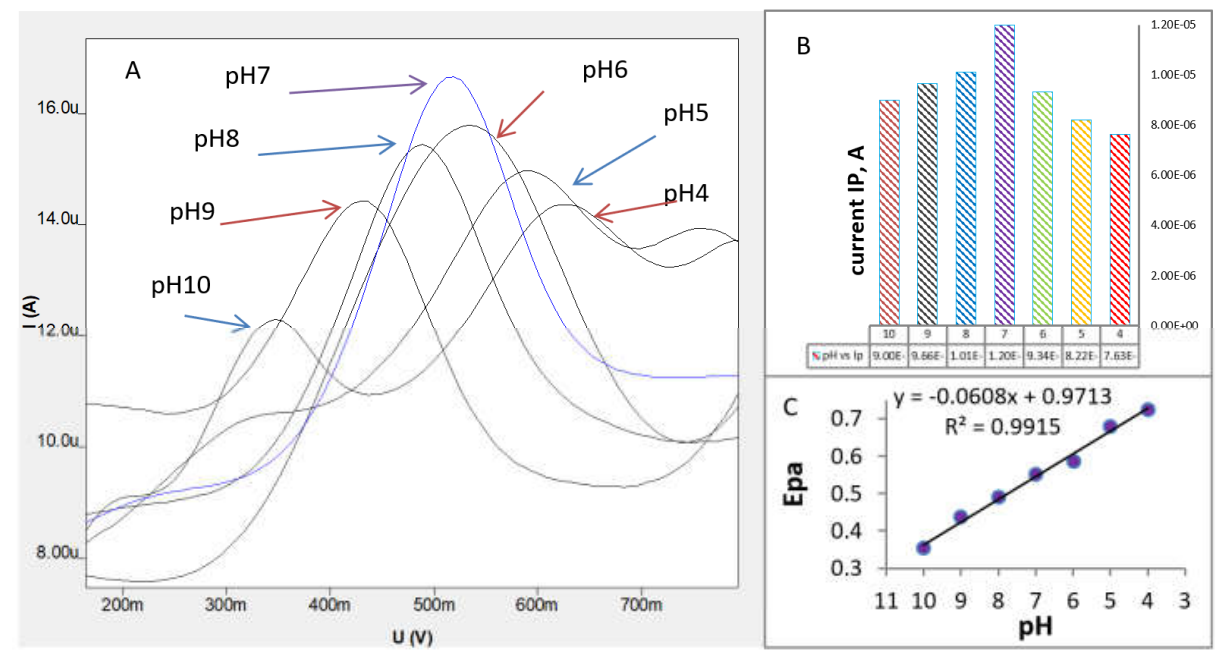

Figure 2. A: SWV for $\mathrm{pH}$ range 4.0-10.0 PBS for INR estimation. B, C: pH effect on INR currents and potentials peak.

The effects of the peak potential (Ep) and peak current (Ip) reversed to $\mathrm{pH}$ are shown in (Figure $2 \mathrm{C}$ ) and through the linear equation that connects the $\mathrm{pH}$ shift relation with (Ep) expressed as follows: Epa $=-60.0 \mathrm{pH}+0.9713$ (Epa in $\mathrm{mV}, \mathrm{r}=0.9957$ ). The slop value is

Bull. Chem. Soc. Ethiop. 2020, 34(2) 
closer to the theoretical $59.8 \mathrm{mV} / \mathrm{pH}$ value. It can be concluded that the INR process of oxidation and reduction requires the transfer of one electron.

Effect of amount of $\mathrm{TiO}_{2 \mathrm{NPS}}$ for INR determination

The effect of quantity $\mathrm{TiO}_{2} \mathrm{NPs}$ on the INR measurement electrode surface was studied after a series of experiments to pick the best amount as shown in Figure 3.

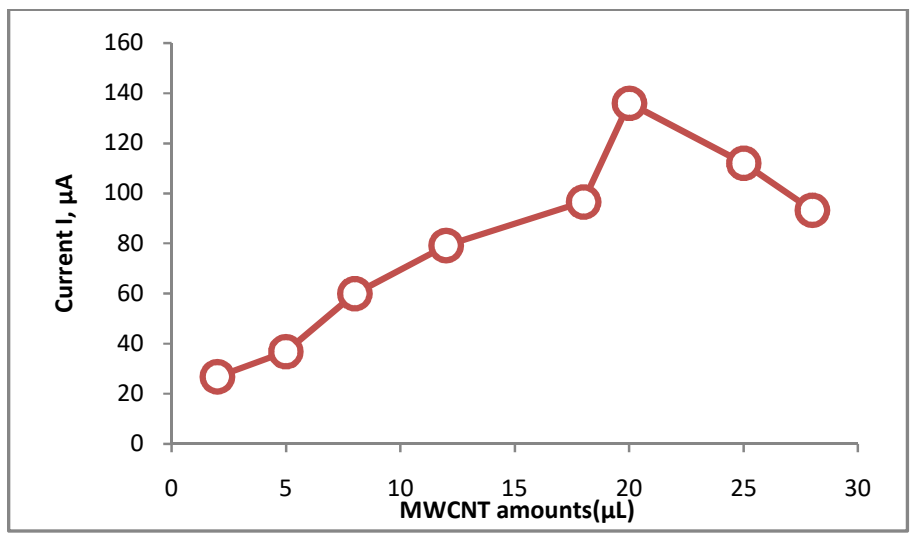

Figure 3. The relationship between the amount of $\mathrm{TiO}_{2 \mathrm{NPs}}$ and the current return to INR.

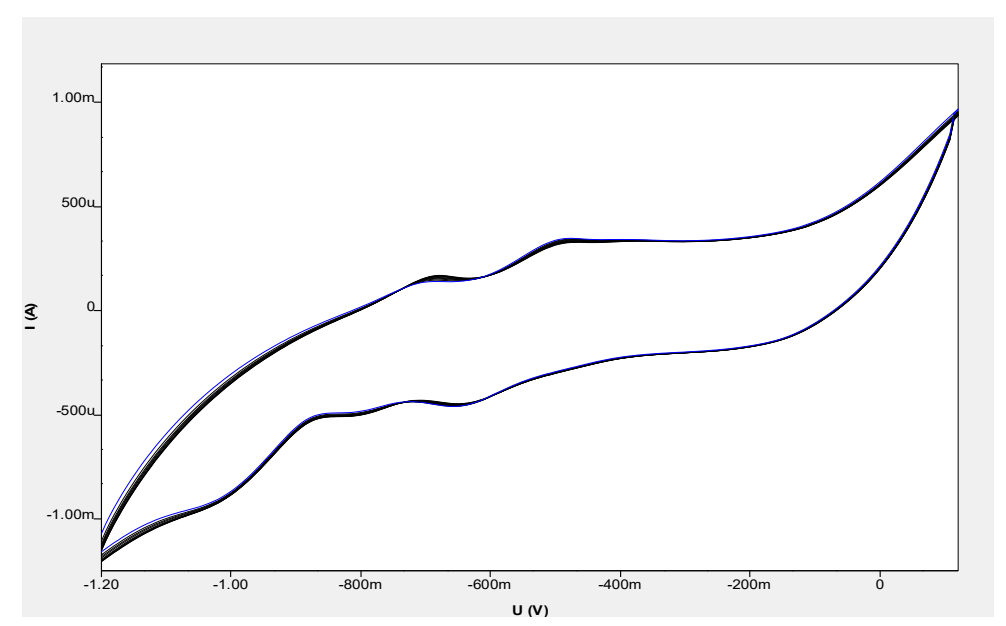

Figure 4. Cyclic voltmograms of electrochemical polymerization $\left(1.0 \times 10^{-4} \mathrm{M}\right)$ of NR.

\section{NR Electro-polymerization on $\mathrm{TiO}_{2 N P S} / \mathrm{GrE}$}

The NR electropolymerisation process is conducted on the graphite surface using the CV method. Figure 4 shows voltammogram within the range of $-1.2-0.2 \mathrm{~V}(\mathrm{Ag} / \mathrm{AgCl})$ for a series of successive cycles using the GrE electrode. At pH 6.0 in 0.2 M phosphate that contains NR 1.0 $\mathrm{x} 10^{-4} \mathrm{M}$ and $0.2 \mathrm{M} \mathrm{KNO}_{3}$. Due to the growth and stability of the oxidation wave value due to 
PNR these conditions are the optimal conditions for NR polymerisation. The resulting wavecurrent is stable after 11 cycles. Hence the number of cycles is chosen as the best geo-geometric transformation effect. The effect is a coating of NR on the graphite GrE surface, which in turn demonstrates the highest electro-polymerisation on the surface of PNR/Gr.

Study the optimum conditions for NR polymerization on $\mathrm{TiO}_{2 N P S} / \mathrm{GrE}$

A number of conditions were studied enhancing electropolymerisation of NR on the electrode surface. These conditions include potential deposition, time of deposition and number of cycles. The NR electropolymerization at $-100 \mathrm{mV}$ and $150 \mathrm{~s}$ which was chosen as a perfect deposition time as shown in Figure 5 was chosen for deposition potential as a first parameter for enhanced. To study the impact of the number of cycles on polymer layer formation using Figure 5, which shows that the current output of the INR measurement was given on the current at 11 cycles and this sum decreased with the increase in the number of cycles indicating the poisoning of the electrode and the blocking of the polymer layer, the communication needed to measure the low INR concentrations.
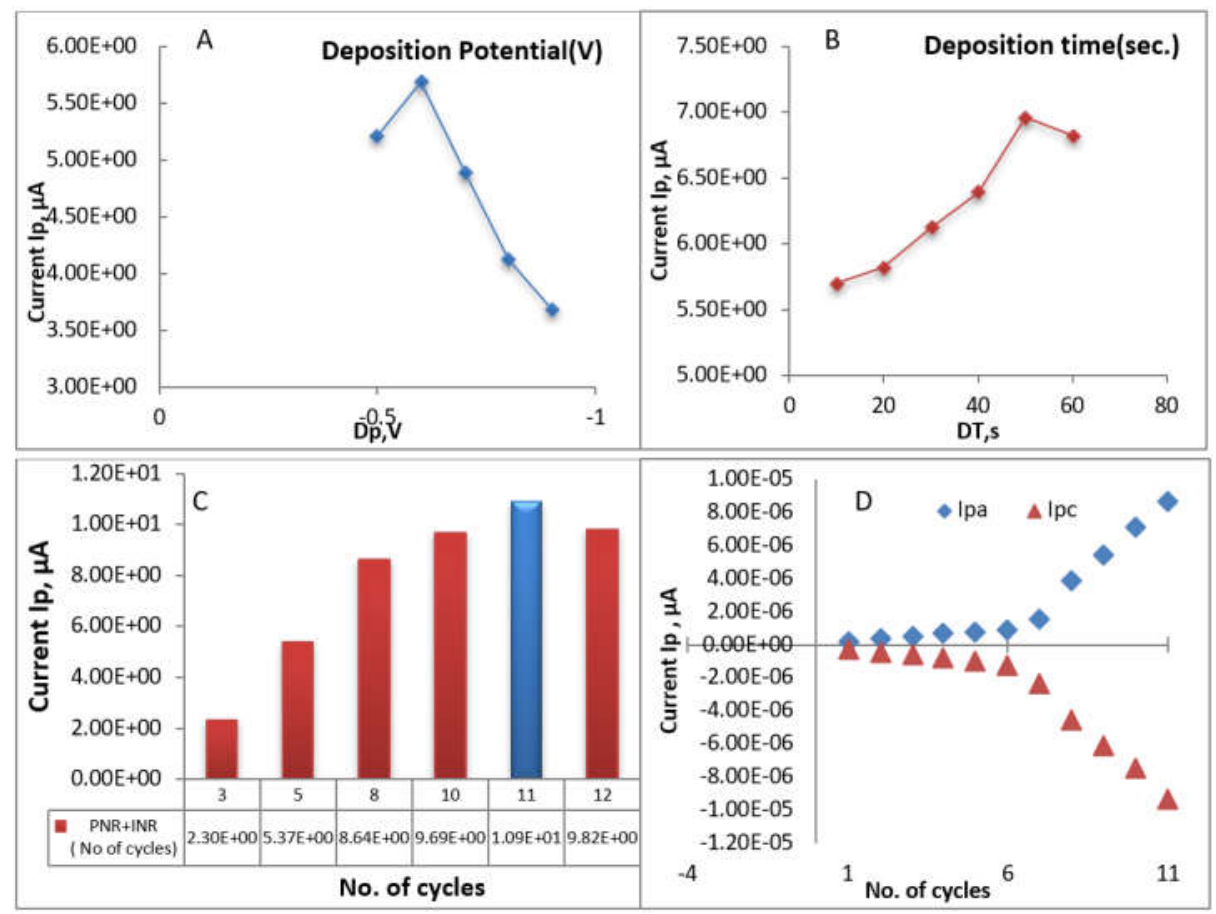

Figure 5. (A, B) effect of deposition potential and time, (C) current results by the oxidative and reduction after peak 12 cycles, (D) relation between current and the number of cycles.

Surface analysis

$\mathrm{PNR} / \mathrm{TiO}_{2 \mathrm{NPS}} / \mathrm{GrE}$ SEM images (Figure 6) were taken under vacuum at a controlled temperature that was obtained to estimate content element concentrations. Via visualization of the electrode surface, which shows the shape of the electrode surface crystals back to the PNR where the images display the order of crystals resulting from process of electrochemical polymerisation. 
Sample micrographs were obtained from the scanning electron microscope, Model Tescan VEGA 3 SB with Instrumental Conditions: 5 HV (Tescan VEGA 3 SB SEM).

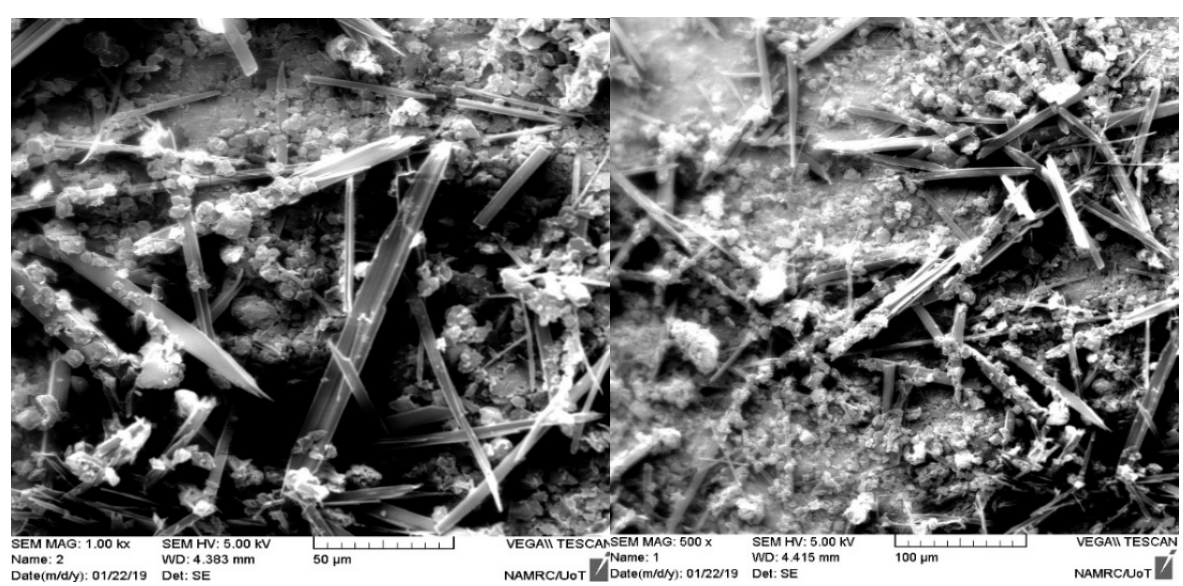

Figure 6. SEM for $\mathrm{PNR} / \mathrm{TiO}_{2 \mathrm{NPS}} / \mathrm{GrE}$.
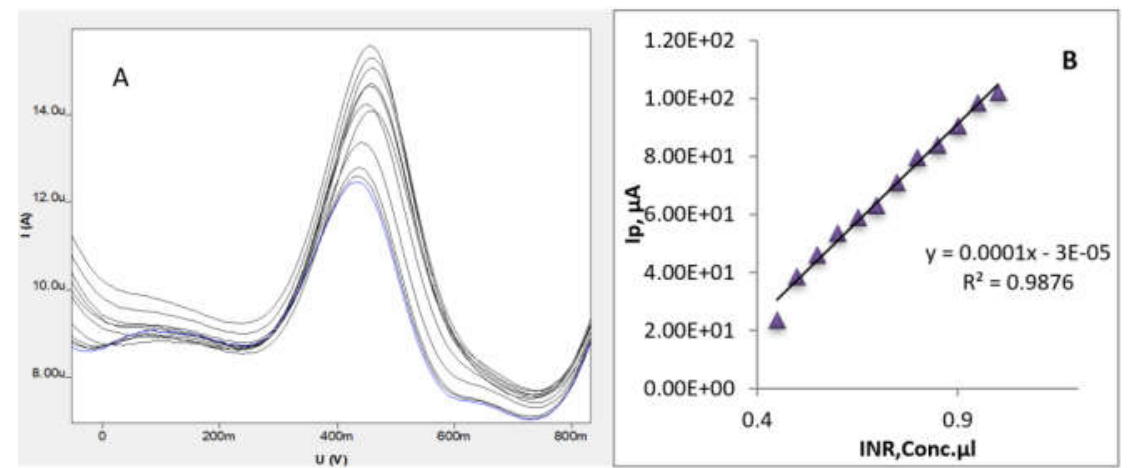

Figure 7. A: SWV for INR on $\mathrm{PNR} / \mathrm{TiO}_{2 \mathrm{NPS}} \mathrm{GrE}$ and $\mathrm{B}$ : calibration plots of INR.

Analytical characteristics of INR estimation

The importance of determining the calibration curve and determining the least possible concentration on the $\mathrm{PNR} / \mathrm{TiO}_{2 \mathrm{NPS}} / \mathrm{GrE}$ surface is determined by the relationship between the INR concentration and the peak current resulting from a set of experiments measured by SWV using different INR concentrations within the range $0.05 \mu \mathrm{M}$ INR at $0.2 \mathrm{M}$ phosphate buffer solution at $\mathrm{pH}$ 7. A more sensitive method of (SWV) technique is preferable for estimating the minimum detection limit. Figure $7 \mathrm{~A}$ shows the $\mathrm{PNR} / \mathrm{TiO}_{2 \mathrm{NPS}} / \mathrm{GrE}$ electrode with different INR concentrations at a deposition potential of $-0.9 \mathrm{~V}$ versus the reference $(\mathrm{Ag} / \mathrm{AgCl})$ electrode. These results suggest a stable and efficient of $\mathrm{PNR} / \mathrm{TiO}_{2 \mathrm{NPS}} / \mathrm{GrE}$. The functional relationship was $\operatorname{Ip}(\mathrm{A})=1.0 \times 10^{-4}[\mathrm{INR}] \mathrm{M}+3.0 \times 10^{-5}(\mathrm{R}=0.993)$.

$\mathrm{TiO}_{2 \mathrm{NPS}}$ was instrumental in improving the INR signal through improved surface electrode efficiency adsorption. To assess the sensor's susceptibility to analyzes, SWV was used to estimate INR, curve INR with added INR concentrations within linear response range 0.5 - 11.5 
$\times 10^{-8} \mathrm{M}$. It is possible to determine the utilization of the voltammogram through the calibration curve shown in Figure 7B. LOD (limit of detection) estimated with following equation [26]:

$\mathrm{LOD}=3.3 \times \mathrm{S}_{\mathrm{y} / \mathrm{x}} / \mathrm{b}$

where $\mathrm{S}_{\mathrm{y} / \mathrm{x}}$ the standard deviation and $\mathrm{b}$ is a slope of plot calibration. INR LOD of about on $\mathrm{PNR} / \mathrm{TiO}_{2 \mathrm{NPS}} / \mathrm{GrE}$ was $8.08 \times 10^{-8} \mathrm{M}$ for $\mathrm{SWV}$ as shown in Table 2 for $\mathrm{n}=10$ sensors and LOQ (limit of quantification) calculating by following equation:

$\mathrm{LOQ}=10 \times \mathrm{S}_{\mathrm{y} / \mathrm{x}} / \mathrm{b}$

with resulting $2.76 \times 10^{-7} \mathrm{M}$ for SWV. The results obtained from Table 2, as well as from the LOD values, LOQ, using 10 different sensors, showing the high stability of the sensor. The 10 sensors gave an average readout of current of $1.37 \times 10^{-5} \mathrm{Ip}$, A with SD $5.3 \times 10^{-7}$.

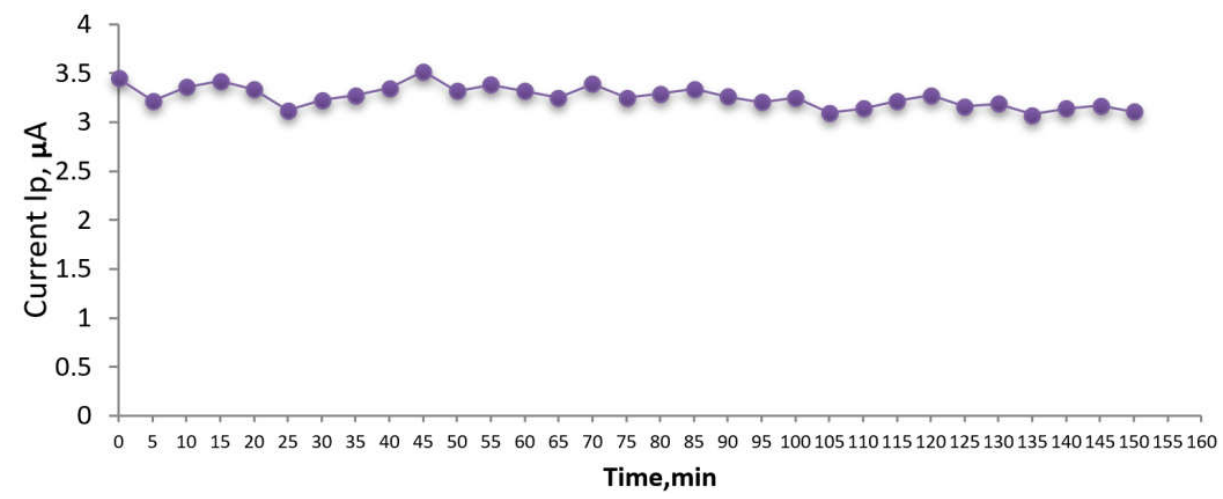

Figure 8. Stability of INR for $150 \mathrm{~min}$.

Table 2. INR determination in serum samples, using PNR/TiO ${ }_{2 \mathrm{NPS}} / \mathrm{GrE}$ electrochemical sensor $(\mathrm{n}=3)$.

\begin{tabular}{|c|c|c|c|c|c|}
\hline $\begin{array}{c}\text { Serum } \\
\text { sample }\end{array}$ & $\begin{array}{c}\text { Concentration } \\
\text { added }(\mu \mathrm{M})\end{array}$ & $\begin{array}{c}\text { Concentration } \\
\text { found in a cell }(\mu \mathrm{M})\end{array}$ & $\begin{array}{c}\text { Concentration } \\
\text { found in a serum }(\mathrm{mM})\end{array}$ & Recovery (\%) & RSD\% \\
\hline 1 & 1.99203 & 1.67075 & 0.083872 & 83.87 & 0.99 \\
\hline 2 & 1.99203 & 1.88823 & 0.094789 & 94.79 & 0.37 \\
\hline 3 & 1.99203 & 1.91325 & 0.096045 & 96.05 & 0.75 \\
\hline 4 & 1.99203 & 1.88473 & 0.094613 & 94.61 & 0.10 \\
\hline 5 & 1.99203 & 1.80649 & 0.090686 & 90.69 & 1.09 \\
\hline 6 & 1.99203 & 1.79317 & 0.090017 & 90.02 & 1.88 \\
\hline 7 & 1.99203 & 1.83472 & 0.092103 & 92.10 & 0.79 \\
\hline 8 & 1.99203 & 1.92669 & 0.09672 & 96.72 & 0.38 \\
\hline 9 & 1.99203 & 1.72607 & 0.086649 & 86.65 & 0.35 \\
\hline 10 & 1.99203 & 1.5906 & 0.079848 & 79.85 & 1.65 \\
\hline 11 & 1.99203 & 1.88049 & 0.094401 & 94.40 & 1.06 \\
\hline 12 & 1.99203 & 1.90342 & 0.095552 & 95.55 & 0.68 \\
\hline 13 & 1.99203 & 1.82504 & 0.091617 & 91.62 & 0.97 \\
\hline 14 & 1.99203 & 1.91298 & 0.096032 & 96.03 & 1.02 \\
\hline 15 & 1.99203 & 1.69037 & 0.084857 & 84.86 & 1.95 \\
\hline 16 & 1.99203 & 1.80352 & 0.090537 & 90.54 & 0.96 \\
\hline 17 & 1.99203 & 1.90673 & 0.095718 & 95.72 & 2.32 \\
\hline 18 & 1.99203 & 1.73657 & 0.087176 & 87.18 & 2.26 \\
\hline 19 & 1.99203 & 1.80264 & 0.090492 & 90.49 & 1.16 \\
\hline 20 & 1.99203 & 1.78562 & 0.089638 & 89.64 & 2.36 \\
\hline
\end{tabular}

Bull. Chem. Soc. Ethiop. 2020, 34(2) 
Repeatability and stability of INR estimation on $P N R / T i O_{2 N P S} / G r E$

The frequency of $\mathrm{PNR} / \mathrm{TiO}_{2 \mathrm{NPS}} / \mathrm{GrE}$ voltammetric readings was checked for a buffer (PBS 0.2 $\mathrm{M}, \mathrm{pH}=7.0$, RSD $3.9 \%$. Stability of the sensor storage was measured after $150 \mathrm{~min}$ of storage and measurements Figure 8 . The sensor retained about $94.9 \%$ of the original response. The results indicate good frequency and stability for the INR estimate. These results, which are due to high stability can be exploited and turned into workable through the exploitation of this study.

\section{Estimation of INR in human serum samples}

Using the SWV technique and the addition process, the INR concentration was calculated using $\mathrm{PNR} / \mathrm{TiO}_{2 \mathrm{NPS}} / \mathrm{GrE}$, using the biosensor to measure the INR concentration in 25 serum sample samples for age group (20-40 years) female chemotherapy patients with lung cancer. Table 2 shows the apparent results of the human serum INR assay suggesting the practical application of such sensors to measure INR in the individual samples.

\section{CONCLUSION}

In this work, an electrochemical sensor was designed to measure and determine INR in human serum samples after the sensor's characteristics were determined, the electrode gave high and stable stability and 94.9 percent of the first reading after a measurement period. In addition to the high stability of serum model measurements by using three vital sensors and the distinctive measurements shown in LOD, LOQ, SD and RSD percentage. All of this is achieved by modified $\mathrm{TiO}_{2 \mathrm{NPS}}$ electrode and $\mathrm{NR}$ electropolymerisation.

\section{REFERENCES}

1. Alpan, A.; Sevil, Z.; István, Z.; Gunes, C.; Borbála, R. Biological activity of bisbenzimidazole derivatives on DNA topoisomerase I and HeLa, MCF7 and A431 cells. $J$. Enzyme Inhib. Med. Chem. 2009, 24, 844-849.

2. Sastre, J.; Puente, J.; Garci'a, J.A.; Diaz-Rubio, E.; Irinotecan in the treatment of elderly patients with advanced colorectal cancer. Crit. Rev. Oncol. Hematol. 2008, 68, 250-255.

3. Wei, L.; Yafei, X.; Yong, L.; Inhibition of SN-38 glucuronidation by gefitinib and its metabolite. Cancer Chemother. Pharmacol. 2015, 75, 1253-1260.

4. David, P.; Keith, J.; Alan, D.; Wasat, M.; Daniel, F.; Martin, E.; Roshan, A.; Michiyasu, I.; Tomohisa, S.; Masaichi, A.; Jeffry, T. Phase II study of TP300 in patients with advanced gastric or gastro-oesophageal junction adenocarcinoma. BMC Cancer. 2016, 16, 779.

5. Bonazza, G.; Tartaggia, S.; Toffoli, G.; Polo, F.; Daniele, S. A fast method for the detection of irinotecan in plasma samples by combining solid phase extraction and differential pulse voltammetry. Anal. Bioanal. Chem. 2020, 412, 1585-1595.

6. Musa, F.; Pothuri, B.; Blank, S.; Ling, H.; Speyer, J.; Curtin, J.; Boyd, L.; Li, X.; Goldberg, J. D.; Muggia, F.; Tiersten, A. Phase II study of irinotecan in combination with bevacizumab in recurrent ovarian cancer. Gynecol. Oncol. 2017, 144, 279-284.

7. Kondo, R.; Watanabe, S.; Shoji, S.; Ichikawa, K.; Abe, T.; Baba, J.; Tanaka, J.; Tsukada, H.; Terada, M.; Sato, K.; Maruyama, Y.; Makino, M.; Hirata, A.; Tanaka, H.; Koya, T.; Yoshizawa, H.; Kikuchi, T. A phase II study of irinotecan for patients with previously treated small-cell lung cancer. Oncol. 2018, 94, 223-232.

8. Bonazza, G.; Tartaggia, S.; Toffoli, G.; Polo, F.; Daniele, S. Voltammetric behavior of the anticancer drug irinotecan and its metabolites in acetonitrile. Implications for electrochemical therapeutic drug monitoring. Electrochim. Acta 2018, 289, 483-493. 
9. Norouzi, P.; Qomi, M.; Nemati A.; Ganjali M.; Determination of anti colon cancer drug, irinotecan by fast Fourier transforms continuous cyclic voltammetry. Int. J. Electrochem. Sci. 2009; 4, 1248-1261.

10. Ganjal, M.; Hariri, M.; Riahi, S.; Norouzi, P.; Javaheri, M. Phenylpropanolamine analysis in formulation and urine by potentiometric membrane sensor. Theoretical investigation. Int. J. Electrochem. Sci. 2009, 4, 295-307.

11. Ganjali, M.; Razavi, T.; Faridbod, F.; Riahi, S.; Norouzi P. Memantine potentiometric membrane sensor for memantine pharmaceutical analysis; Computational investigation. Int. J. Electrochem. Sci. 2009, 4, 1138-1152.

12. Vijayalakshmi, A.; Thamarai, J. Calcium ion selective electrode based on vinyl acetic acid grafted PVC ionophore and determination of thermodynamic functions and its analytical application. JUC 2017, 13, 40-43.

13. Javanbakht, M.; Mohammadi, A.; Ganjali, R.; Norouzi, P.; Faridbod, F.; Pirelahi, H. PVC based on thiopyrilium derivatives membrane electrodes for determination of histamine. $J$. Chinese Chem. Soc. 2007, 54, 1495-1504.

14. Hemn, A.; Nabil, A. Spectrophotometric determination of promethazine hydrochloride in pure and pharmaceutical dosage forms. ZJPAS 2017, 29, 107-114.

15. Faridbod, F.; Ganjali, M.R.; Labbafi, S.; Riahi, S.; Norouzi, P. A new metoclopramide potentiometric membrane sensor for analysis in pharmaceutical formulation and urine: Concerns to theoretical study. Int. J. Electrochem. Sci. 2009, 4, 772-786.

16. Norouzi, P.; Dinarvand, R.; Ganjali, M.R.; Moosavi-Movahedi, A.; Saboury A., Tamaddon, A. Application of adsorptive voltammetry for the detection of sub-nano molar cyclizine in biological fluids and tablets using fast Fourier transform continuous cyclic voltammetry in a flowing system. Anal. Sci. 2009, 25, 505-510.

17. Ganjali M.; Memari Z.; Riahi S.; Faridbod,F.; Norouzi, P.; Manesha A. A new homatropine potentiometric membrane sensor as a useful device for homatropine hydrobromide analysis in pharmaceutical formulation and urine: A computational study. J. Brazil. Chem. Soc. 2009, 25, 926-934.

18. Javanbakht, M.; Safaraliee, L.; Ganjali, M.; Abdouss, R.; Norouzi, M.; Faridbod, F.; Fard, S. Design of an imipramine-selective electrode based on an ion-pair and its application to pharmaceutical analysis. J. Chinese Chem. Soc. 2009, 56, 296-302.

19. Mariska, K.; Oppel, G.; Lizelle, F.; Prashilla, S. Increased autonomic dysfunction in subjects treated with alpha-methyldopa. Int. J. Med. Pharm. 2015, 3, 27-39.

20. Daneshgar, P.; Norouzi, P.; Ganjali, M.; Dousty, F. A dysprosium nanowire modified carbon paste electrode for determination of nanomplar level of diphenhydramin by continuous square wave voltammetry in flow injection system. Int. J. Electrochem. Sci. 2009, 4, 444-457.

21. Suzan, Y.; Dilsat, O.; Selehattin, Y. Electrochemical biosensor for brca1 gene and tamoxifen interaction. J. Sci. Perspect. 2020, 4, 35-48.

22. Haijan, R.; Huat, T.G. Electrochemical study on the interaction of irinotecan with calf thymus double stranded DNA. Chin. J. Chem. 2012, 30, 738-742.

23. Ummy, M.; Christophe, I.; Haytem, J.; Marc, C.; Suryo, G. Electropolymerized Neutral Red as redox mediator for yeast fuel cell. Int. J. Electrochem. Sci. 2015, 10, 8886-8898.

24. Majeed, M.; Al-jawadi, E. Electrochemical biosensor hemoglobin immobilization determination of the breast cancer drug (adriamycin). Raf. J. Sci. 2019, 28, 152-163.

25. Al-jawadi, E.; Majeed, M. Electrochemical sensors based on poly (L-phenyl alanine) film on MWCNT for determination of TPS. Periódico Tchê Química 2020, 17, 579-590.

26. Tara, F.; Aryan, F.; Musher, I. Essa Q. L-Tryptophan as fluorescent probe for determination of folic acid in pharmaceutical products. Aro-The Scientific Journal of Koya University 2019, 7, 19-26. 